\title{
EFFECTIVENESS OF NEEM, GARLIC AND RED CHILI AGAINST ADULT DERMESTID BEETLE IN SUN DRIED FISH
}

\author{
A. K. M. Nowsad, R. Mondal and M. R. Islam \\ Department of Fisheries Technology, Bangladesh Agricultural University \\ Mymensingh-2202, Bangladesh
}

\begin{abstract}
The suitability of neem (Azadirachta indica), garlic (Allium sativum) and red chili (Capsicum frutescens) in repelling insects in dried fish during processing and storage was determined. Their acetone extracts were used to evaluate toxic effects against adult dermestid beetle, Dermestes sp. The concentration of plant extracts were $60 \%, 80 \%$ and $100 \%$ for adult Dermestes sp. The $\mathrm{LC}_{50}$ values of neem, garlic and red chili were $1.81 \%, 4.85 \%$ and $1.11 \%$, respectively at 24 hours after treatment (HAT), indicating that red chili was the most toxic plant. Red chili possessed the highest toxic effect at $48 \mathrm{HAT}(0.87 \%)$ and $72 \mathrm{HAT}(0.03 \%)$. It was observed that all of the three plant extracts had repellent action on adult Dermestes sp. The highest mean repellency was observed in neem extract (62.67\%) followed by red chili $(38.44 \%)$ and garlic (31.11\%). Repellent effects increased with the concentration of plant extracts.
\end{abstract}

Key words : Botanical pesticides, Dermestid beetle, Toxic effects, Dried fish, Repellent effects

\section{INTRODUCTION}

About $20 \%$ of the total fish caught annually in Bangladesh are sun dried and mostly consumed by the domestic market. One of the major problems associated with the sundrying of fish is the infestation of the products by the blow fly and beetle larvae (Nowsad, 2005). In tropical climates under highly humid conditions, heavy infestation of unsalted dry fish by beetles may cause up to $30 \%$ loss of the products (Bala and Mondol, 2001). The other problems markedly evident with dried fish are the contamination during different stages of handling and the indiscriminate use of various pesticides (Nowsad, 2005). Dried fish contaminated by both insects and insecticides comprises about $60 \%$ of the total dried products that is considered not fit for human consumption (Neuschler, 1998).

Dried fish is readily attacked by several species of dermestid beetle, including Dermestes maculatus, $D$. frischii and $D$. ater. These insects are generally associated with dried fish especially during storage, transportation and marketing (Don-Pedro, 1989). Use of unsafe insecticides and their excessive dosages in dried fish create serious health problems to the consumers (Khan et al., 2002). DDT has been found to be in excessive quantity in different dried fish products in Bangladesh, the level of which are much higher than the FAO 
allowable limit of $0.5 \mathrm{mg} / \mathrm{kg}$ (Khan et al., 2002) or FDA approved tolerance, action and guidance level of 5 ppm (FDA, 1996).

Botanical pesticides are generally considered to be safe when compared to synthetic chemical pesticides; they are considered to be non-toxic to mammals, birds and fish (Ascher, 1993) and cause less disturbance to ecosystems than chemical insecticides (Sundaram, 1996). There has been no evidence of the development of resistance of crude neem products to date, although there has been some evidence of the development of resistance of purified azadirachtin (Jilani et al., 1990; Ascher, 1993). Garlic and chili are also considered to be safe for human. Nonetheless all the three botanical pesticides have extra health benefit to the man (Ascher, 1993). Considering such advantages, the suitability of their use in dried fish was tested through investigating the toxic and repellent effects of neem, red chili and garlic against a common dried fish beetle Dermestes sp.

\section{MATERIALS AND METHODS}

The present study was conducted in the Microbiology Laboratory of the Department of Fisheries Technology, Bangladesh Agricultural University (BAU). Selected plants were tested to determine their toxic and repellent effects on the beetles and mites of various dried fish purchased from the fish markets.

\section{Collection and rearing of insect}

The test insect species, Dermestes sp. (adult) was collected from dried fish markets of Mymensingh, Bangladesh. The insects were maintained in the postgraduate laboratory of Faculty of Fisheries, BAU at $27-30^{\circ} \mathrm{C}$. The insects were reared with dried fish in plastic jars.

\section{Collection of plant materials}

Neem leaves were collected from the BAU, Mymensingh. Red pepper and garlic were purchased from K. R. Market, BAU, Mymensingh. After bringing them to the laboratory, they were washed in running water. The plant materials were first kept in shade for air drying and then they were dried in a hot air electric oven at $60^{\circ} \mathrm{C}$ to gain constant weight.

\section{Preparation of plant dust}

Dusts were prepared by pulverizing the dried plant materials with the help of a grinder. Then the dusts were passed through a 25-mesh diameter sieve to obtain fine and uniform dust. The dust was preserved in airtight condition in zip-lock polythene bags till their use in extract preparation.

\section{Preparation of plant extracts}

Ten gram of each category of the dusts were taken in a $500 \mathrm{ml}$ beaker and separately mixed with $100 \mathrm{ml}$ acetone. Then the mixture was stirred for 30 minutes by a magnetic 
stirrer (at $3000 \mathrm{rpm}$ ) and left to stand for 24 hours. The mixture was then filtered through a fine cloth and again through a filter paper (Whatman No. 1). The filtered materials were taken into a round bottom flask and condensed by evaporation of solvent in a water bath at $45^{\circ} \mathrm{C}$. Evaporation was done to make the volume of $10 \mathrm{ml}$. Condensed extracts were preserved in tightly corked labeled bottles and stored in a refrigerator until their use for insect bioassays.

\section{Preparation of stock solution}

Stock solutions of plant extracts were prepared separately by diluting the condensed extracts with acetone. Different concentrations like $60 \%, 80 \%$ and $100 \%$ of each category of plant extract were prepared by dissolving the stock solutions in acetone prior to insect bioassay.

\section{Disinfestations of dried fish}

Sun dried fish were kept in an oven at $45^{\circ} \mathrm{C}$ for 2-3 hours, packed in polythene bag and sealed to avoid future infestation.

\section{Insect bioassays}

Insect bioassay was conducted in the Microbiology laboratory of the Faculty of Fisheries at 27 to $30^{\circ} \mathrm{C}$ to determine direct toxicity and repellency against adult Dermestes sp.

\section{Direct toxicity test}

Direct toxicity was determined according to the method of Talukder and Howse (1993). Three different concentrations of each plant extracts $(60,80$ and $100 \%)$ were prepared with respective solvents. Then $30 \mu \mathrm{l}$ of prepared solution was applied to the dorsal surface of the thorax of each insect by touching with a micropipette. Ten insects (five males \& five females) per replication were treated and each treatment was replicated 3 times. In addition, the same numbers of insects were treated with solvent only for control. After treatment, the insects were transferred into $9 \mathrm{~cm}$ diameter petridishes (10 insects/petridish) containing dried fish. Insect mortalities were recorded at 24, 48 and 72 HAT. Original data were corrected by Abbott's (1987) formula as follows :

$$
\mathrm{P}=\frac{\mathrm{P}^{\prime}-\mathrm{C}}{100-\mathrm{C}} \times 100
$$

Where,

$$
\begin{aligned}
& \mathrm{P}=\text { Percentage of corrected mortality } \\
& \mathrm{P}^{\prime}=\text { Observed mortality }(\%) \\
& \mathrm{C}=\text { Control mortality }(\%)
\end{aligned}
$$

\section{Repellency test}

Repellency test was conducted according to the method of Talukder and Howse (1994). Petridishes with semi powdered dried fish were divided into two parts, treated and untreated with a sharp dividing line at the centre. With the help of a pipette, $1 \mathrm{ml}$ 
solution of each plant extract was applied to one half of the dried fishes. The treated half was then air-dried. Ten insects (five males and five females) were released at the centre dividing line of each petridish and a cover was placed on the petridish. For each plant extract and each dose, three replications were used. Then the insects present on each portion were counted at hourly intervals up to fifth hour.

The data were expressed as percentage repulsion (PR\%) by the following formula :

$$
\mathrm{PR}(\%)=(\mathrm{NC}-50) \times 2
$$

Where,

$\mathrm{NC}=$ The percentage of insects present in the control half.

Positive (+) values expressed repellency and negative (-) values attractency.

Data (PR\%) were analyzed using analysis of variance (ANOVA). The average values were then categorized according to the following class according to Mc Donald et al., (1970).

\begin{tabular}{c|c}
\hline Class & Repellency rate $(\%)$ \\
\hline 0 & $>0.01$ to 0.1 \\
I & 0.1 to 20 \\
II & 20.1 to 40 \\
III & 40.1 to 60 \\
IV & 60.1 to 80 \\
V & 80.1 to 100 \\
\hline
\end{tabular}

\section{Statistical analysis}

The experimental data were analysed by a completely randomized design (factorial CRD) using MSTAT statistical software. The mean values were compared by Duncan's Multiple Range Test (DMRT) (Duncan, 1951). The $\mathrm{LC}_{50}$ values were calculated by using probit analysis (Finney, 1971).

\section{RESULTS AND DISCUSSION}

\section{Direct toxic effect}

Direct toxic effects of different plant extracts on adult Dermestes sp. in dried fish at different (HAT have been shown in Table 1 and Table 2. Application of red chili to Dermestes sp. produced the highest initial mortality. Scngypt and Ray (1987) found similar results with red chili that might be due to the presence of piperine. The order of toxicity of the three plant extracts on Dermestes sp. were, red chili > neem > garlic. It was found that the mortality percentage was also directly proportional to the level of concentration of plant extract. In Table 1 average mortality percentage was $65.56 \%$ for red 
chili extract, $49.44 \%$ for neem extract and $28.33 \%$ for garlic extract. In Table 2 average mortality percentage was $50.741 \%$ for $60 \%$ dose, $63.70 \%$ for $80 \%$ dose and $65.56 \%$ for $100 \%$ dose of extract. So naturally, $100 \%$ dose was more toxic. In Table 3 highest mortality percentage was found at $93.33 \%$ for $100 \%$ red chili extract. Lowest average mortality percentage was found at $25.56 \%$ for $60 \%$ garlic extract. The interaction effects of plant, dose and time had no significant effect on the mortality of adult Dermestes sp. except their average values.

Table 1. Direct toxic effect of different plant extracts on adult Dermestes sp. in treated dried fish at different HAT (interaction of plant and time).

\begin{tabular}{l|c|c|c|c}
\hline \multirow{2}{*}{ Name of the plants } & \multicolumn{3}{|c|}{ Mortality percentage } & \multirow{2}{*}{ Average } \\
\cline { 2 - 4 } & 24 HAT & 48 HAT & 72 HAT & \\
\hline Neem & 41.67 & 50.00 & 56.67 & $49.44^{\mathrm{b}}$ \\
Red chili & 61.67 & 65.83 & 69.17 & $65.56^{\mathrm{a}}$ \\
Garlic & 19.17 & 28.33 & 37.50 & $28.33^{\mathrm{c}}$ \\
\hline
\end{tabular}

HAT $=$ Hours after treatment

Within column values followed by different superscripts are significantly different $(\mathrm{P}<0.01)$.

Table 2. Direct toxic effect of doses of different plant extracts on adult Dermestes sp. in treated dried fish at different HAT (interaction of dose and time).

\begin{tabular}{l|c|c|c|c}
\hline \multirow{2}{*}{ Doses (\%) } & \multicolumn{3}{|c|}{ Mortality percentage } & \multirow{2}{*}{ Average } \\
\cline { 2 - 4 } & $24 \mathrm{HAT}$ & $48 \mathrm{HAT}$ & $72 \mathrm{HAT}$ & \\
\hline Control & 10.00 & 10.00 & 13.33 & $11.11^{\mathrm{c}}$ \\
60 & 41.11 & 52.22 & 58.89 & $50.74^{\mathrm{b}}$ \\
80 & 55.56 & 64.44 & 71.11 & $63.70^{\mathrm{a}}$ \\
100 & 56.67 & 65.56 & 74.44 & $65.56^{\mathrm{a}}$ \\
\hline
\end{tabular}

HAT $=$ Hours after treatment

Within column values followed by different superscripts are significantly different $(\mathrm{P}<0.01)$.

\section{Probit analysis of direct toxic effect}

The results of the probit analysis for the estimation of $\mathrm{LC}_{50}$ values and their $95 \%$ fiducial limits and the slope of regression lines at 24, 48 and $72 \mathrm{HAT}$ for the mortality of Dermestes sp. are presented in Table 4 . The $\mathrm{LC}_{50}$ values of neem, red chili and garlic showed 1.81, $1.11,4.85 \%$ toxicity at $24 \mathrm{HAT} ; 1.77,0.87,2.30 \%$ at $48 \mathrm{HAT}$ and $1.05,0.03$ and $1.87 \%$ at 72 HAT respectively. From the above probit results, it was clear that all tested plants were more or less effective for controlling adult Dermestes sp. but red chili was the most effective plant. 
Table 3. Direct toxic effect of different plant extracts at different dose level on adult Dermestes sp. in treated dried fish at different HAT (interaction of plant, dose and time)

\begin{tabular}{l|c|c|c|c|c}
\hline \multirow{2}{*}{ Name of the plants } & \multirow{2}{*}{ Doses (\%) } & \multicolumn{3}{|c|}{ Mortality percentage } & \multirow{2}{*}{ Average } \\
\cline { 3 - 5 } & & $24 \mathrm{HAT}$ & $48 \mathrm{HAT}$ & $72 \mathrm{HAT}$ & \\
\hline Control & - & 10.00 & 10.00 & 13.33 & $11.11^{\mathrm{d}}$ \\
\hline Neem & 60 & 50.00 & 60.00 & 70.00 & $60.00^{\mathrm{b}}$ \\
& 80 & 53.33 & 63.33 & 70.00 & $62.22^{\mathrm{b}}$ \\
& 100 & 53.33 & 66.667 & 73.33 & $64.44^{\mathrm{b}}$ \\
\hline Red chili & 60 & 60.00 & 66.67 & 73.33 & $66.67^{\mathrm{b}}$ \\
& 80 & 86.7 & 93.33 & 93.33 & $91.11^{\mathrm{a}}$ \\
& 100 & 90.00 & 93.33 & 96.67 & $93.33^{\mathrm{a}}$ \\
\hline Garlic & 60 & 13.33 & 30.00 & 33.33 & $25.56^{\mathrm{c}}$ \\
& 80 & 26.67 & 36.67 & 50.00 & $37.78^{\mathrm{c}}$ \\
& 100 & 26.67 & 36.67 & 53.33 & $38.89 \mathrm{c}$ \\
\hline
\end{tabular}

HAT $=$ Hours after treatment

Within column values followed by different superscripts are significantly different $(\mathrm{P}<0.01)$.

Table 4. Relative toxicity of different plant extracts treated against adult Dermestes sp. at 24, 48 and 72 HAT

\begin{tabular}{l|c|c|c|c|c}
\hline Name of the extracts & $\begin{array}{c}\text { No. of the } \\
\text { insect used }\end{array}$ & LC50 values & $\begin{array}{c}95 \% \text { fiducial } \\
\text { limit }\end{array}$ & $\begin{array}{c}\chi^{2} \\
\text { values }\end{array}$ & Slope \pm DE \\
\hline \multicolumn{5}{|c}{ 24 HAT } \\
\hline Neem & 10 & 1.81 & $-4.88-5.40$ & 0.089 & $1.18 \pm 0.83$ \\
Red chili & 10 & 1.11 & $-4.89-4.99$ & 0.009 & $0.35 \pm 0.79$ \\
Garlic & 10 & 4.85 & $-4.99-6.37$ & 0.0002 & $1.06 \pm 0.92$ \\
\hline \multicolumn{5}{c}{48 HAT } \\
\hline Neem & 10 & 1.77 & $-5.40-5.90$ & 0.162 & $2.19 \pm 0.91$ \\
Red chili & 10 & 0.87 & $-4.69-5.08$ & 0.084 & $2.36 \pm 0.81$ \\
Garlic & 10 & 2.30 & $-4.74-3.58$ & 0.026 & $0.85 \pm 0.82$ \\
\hline \multicolumn{5}{c}{72 HAT } \\
Neem & 10 & 1.05 & $-4.96-4.99$ & 0.014 & $1.12 \pm 0.80$ \\
Red chili & 10 & 0.03 & $-6.67-3.38$ & 0.011 & $-0.41 \pm 0.84$ \\
Garlic & 10 & 1.87 & $-4.69-5.23$ & 0.009 & $0.36 \pm 0.80$ \\
\hline
\end{tabular}

HAT $=$ Hours after treatment

Values were based on one solvent, three concentrations and three replications of 10 insects each.

$\chi^{2}=$ Goodness of fit. 


\section{Probit regression lines}

The insect mortality rate showed positive correlation with the doses in all cases. The probit regression lines for the effects of three different plant extracts showed a clear linear relationship between probit-mortality and the doses used for them. The calculated probit regression equation of neem extracts at $24 \mathrm{HAT}$ was $\mathrm{Y}=2.7467 \mathrm{x}+0.0155$, at $48 \mathrm{HAT}$ was $\mathrm{Y}=3.3411 \mathrm{x}+0.0046$ and for 72 HAT was $\mathrm{Y}=3.7339 \mathrm{x}+0.0301$ (Fig. 1). For red chili extracts equations were at 24 HAT: $\mathrm{Y}=4.8255 \mathrm{x}-0.1342$, at $48 \mathrm{HAT}, \mathrm{Y}=5.1372 \mathrm{x}-0.1084$ and at 72 HAT $Y=5.3146 x-0.0808$ (Fig. 2). For garlic extracts equations were: at 24 HAT, $\mathrm{Y}=1.3863 \mathrm{x}-0.0717$, at 48 HAT $\mathrm{Y}=2.0725 \mathrm{x}-0.0154$ and for 72 HAT $\mathrm{Y}=2.805 \mathrm{x}-0.095$ (Fig. 3). All of these equations indicated similar results that mortality rate increased with the increased of concentration and time. Highest mortality was at 72 HAT.

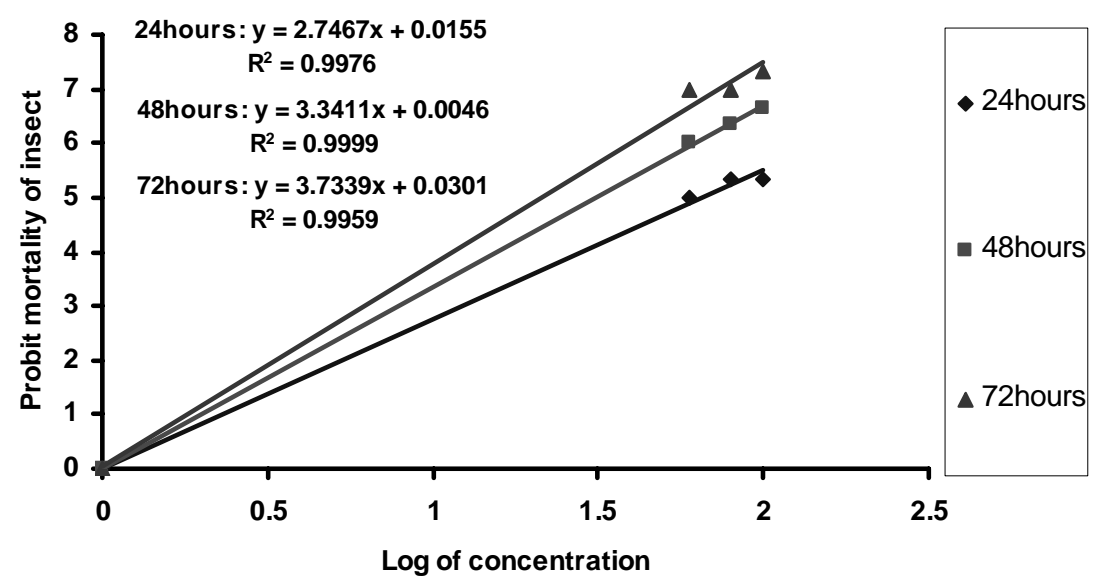

Fig. 1. Relationship between probit mortality and log doses of neem extracts on adult Dermestes sp. at 24, 48 and 72 hours after treatment

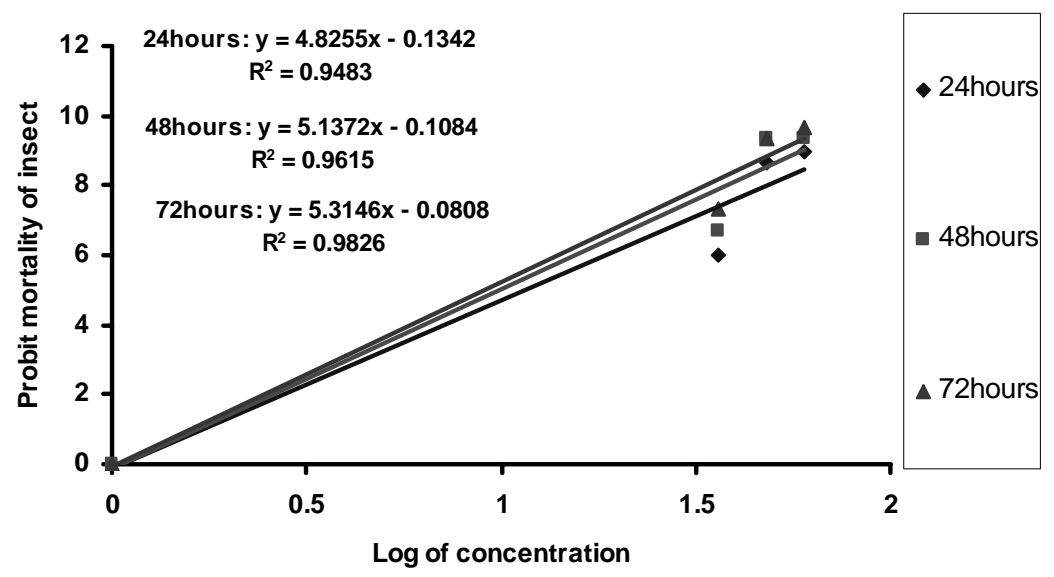

Fig. 2. Relationship between probit mortality and log doses of red chili extracts on adult Dermestes sp. at 24, 48 and 72 hours after treatment 


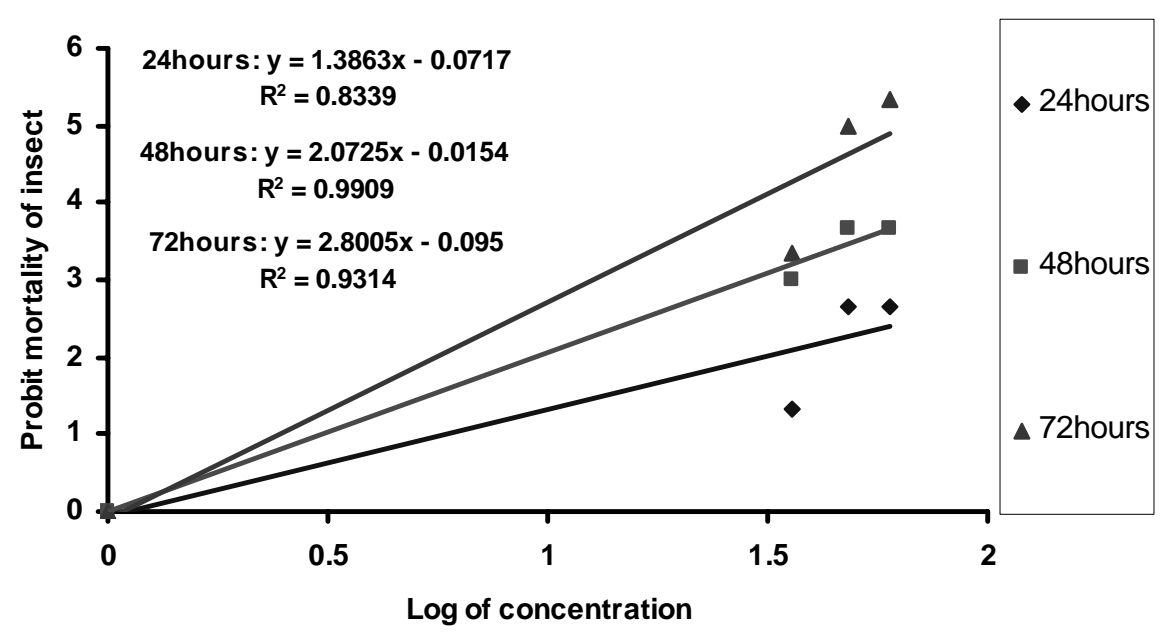

Fig. 3. Relationship between probit mortality and log doses of garlic extracts on adult Dermestes sp. at 24,48 and 72 hours after treatment

\section{Repellent effect}

Table 5 shows the repellent effects of different plant extracts. Among the three plant extracts tested, neem showed the highest $(62.67 \%)$ mean repellency effect followed by red chili $(38.44 \%)$ and garlic $(31.11 \%)$. On the basis of mean repellency rate the repellency class for red chili was II, for neem was IV and for garlic was II (Table 5). The repellency effects of different plant extracts at different dose level on Dermestes sp. are presented on Table 6 . The highest $(56.66 \%)$ mean repellency was found at $100 \%$ concentration level and the lowest $(31.56 \%)$ was found at $60 \%$ concentration level. Table 7 showed that the highest $(82.67 \%)$ mean repellency was found with $100 \%$ neem extract and the lowest $(20 \%)$ mean repellency was found with $60 \%$ garlic extract. From the above results, it was found that neem extracts showed more repellent effect than other plant extracts.

Table 5. Repellent effect of different plant extracts on Dermestes sp. in treated dried fish at different HAT (interaction of plant and time)

\begin{tabular}{l|c|c|c|c|c|c|c}
\hline \multirow{2}{*}{$\begin{array}{c}\text { Name of the } \\
\text { plants }\end{array}$} & \multicolumn{5}{|c|}{ Repellency rate } & Mean & $\begin{array}{c}\text { Repellency } \\
\text { class }\end{array}$ \\
\cline { 2 - 5 } & 1 HAT & 2 HAT & 3 HAT & 4 HAT & 5 HAT & repellency & IV \\
\hline Neem & 64.64 & 64.64 & 57.78 & 66.67 & 60.00 & $62.67 \mathrm{a}$ & II \\
Red chili & 36.67 & 26.67 & 33.33 & 48.89 & 46.67 & $38.44^{\mathrm{b}}$ & $\mathrm{II}$ \\
Garlic & 33.33 & 30.00 & 30.00 & 31.11 & 31.11 & $31.11^{\mathrm{c}}$ & $\mathrm{II}$ \\
\hline
\end{tabular}

HAT $=$ Hours after treatment

Within column values followed by different letters are significantly different $(\mathrm{P}<0.01)$. 
Table 6. Repellent effect of doses of different plant extracts on Dermestes sp. in treated dried fish at different HAT (interaction of dose and time)

\begin{tabular}{l|c|c|c|c|c|c|c}
\hline \multirow{2}{*}{ Doses (\%) } & \multicolumn{5}{|c|}{ Repellency rate } & Mean & $\begin{array}{c}\text { Repellency } \\
\text { class }\end{array}$ \\
\cline { 2 - 5 } & 1 HAT & 2 HAT & 3 HAT & 4 HAT & 5 HAT & II \\
\hline 60 & 35.56 & 26.67 & 31.11 & 33.33 & 31.11 & $31.56^{\mathrm{c}}$ & II \\
80 & 46.67 & 38.89 & 36.67 & 51.11 & 46.67 & $44.00^{\mathrm{b}}$ & III \\
100 & 52.22 & 55.56 & 53.33 & 62.22 & 60.00 & $56.67 \mathrm{a}$ & III \\
\hline
\end{tabular}

HAT $=$ Hours after treatment

Within column values followed by different letters are significantly different $(\mathrm{P}<0.01)$.

Table 7. Repellent effect of different plant extracts at different dose level on Dermestes sp. in treated dried fish at different HAT (interaction of plant, dose and time)

\begin{tabular}{|c|c|c|c|c|c|c|c|c|}
\hline \multirow{2}{*}{$\begin{array}{l}\text { Name of } \\
\text { the plants }\end{array}$} & \multirow{2}{*}{$\begin{array}{c}\text { Doses } \\
(\%)\end{array}$} & \multicolumn{5}{|c|}{ Repellency rate } & \multirow{2}{*}{$\begin{array}{l}\text { Mean } \\
\text { repellency }\end{array}$} & \multirow{2}{*}{$\begin{array}{c}\text { Repellency } \\
\text { class }\end{array}$} \\
\hline & & $1 \mathrm{HAT}$ & 2 HAT & 3 HAT & $4 \mathrm{HAT}$ & 5 HAT & & \\
\hline \multirow[t]{3}{*}{ Neem } & 60 & 46.67 & 33.33 & 33.33 & 40.00 & 33.33 & $37.33^{\mathrm{cd}}$ & II \\
\hline & 80 & 66.67 & 73.33 & 60.00 & 73.33 & 66.67 & $68.00^{\mathrm{b}}$ & IV \\
\hline & 100 & 80.00 & 86.67 & 80.00 & 86.67 & 80.00 & $82.67 \mathrm{a}$ & V \\
\hline \multirow[t]{3}{*}{ Red chili } & 60 & 40.00 & 26.67 & 40.00 & 40.00 & 40.00 & $37.33^{\mathrm{cd}}$ & II \\
\hline & 80 & 40.00 & 20.00 & 20.00 & 53.33 & 46.67 & $36.00 \mathrm{~cd}$ & II \\
\hline & 100 & 30.00 & 33.33 & 40.00 & 53.33 & 53.33 & $42.00^{c}$ & III \\
\hline \multirow[t]{3}{*}{ Garlic } & 60 & 20.00 & 20.00 & 20.00 & 20.00 & 20.00 & $20.00 \mathrm{e}^{\mathrm{e}}$ & I \\
\hline & 80 & 33.33 & 23.33 & 30.00 & 26.67 & 26.67 & $28.00 \mathrm{de}$ & II \\
\hline & 100 & 46.67 & 46.67 & 40.00 & 46.67 & 46.67 & $45.33^{c}$ & III \\
\hline
\end{tabular}

HAT $=$ Hours after treatment

Within column values followed by different letters are significantly different $(\mathrm{P}<0.01)$.

\section{CONCLUSION}

The $\mathrm{LC}_{50}$ values of red chili, neem and garlic were $1.11 \%, 1.81 \%$ and $4.85 \%$, respectively at $24 \mathrm{HAT}$, which indicated that red chili was the most toxic against adult demisted beetle. Red chili possessed the highest toxic effect at 48 HAT $(0.87 \%)$ and 72 HAT $(0.03 \%)$. All of the three plant extracts had repellent action on adult Dermestes sp. in dried fish. The highest mean repellency was observed in neem (62.67\%) extract followed by red chili $(38.44 \%)$ and garlic $(31.11 \%)$. Repellent effects increased proportionally with the concentration of plant extracts. It was thus concluded that treated botanical materials had both repellent and toxic effects against demisted beetles. 


\section{REFERENCES}

Abbott, W. S. 1987. A method of computing the effectiveness of an insecticide. J. American Mosquito Cont. Assoc., 3: 302-303.

Ascher, K. R. S. 1993. Non-conventional insecticidal effects of pesticides available from the neem tree, Azadirachta indica. Archives of Insect Biochemistry and Physiol., 22: 433-449.

Bala, B. K. and M. R. A. Mondal. 2001. Experimental investigation of solar drying of fish using tunnel dryer. Drying Technol., 19(2): 1-10.

Don-Pedro, K. N, 1989, "Insecticidal activity of some vegetable oils against D. macaluttus, Degeer Coleoptera; Dermestidae on dried fish." J. Stored Prod Res., 25(2): 81-86.

Duncan, D. B. 1951. A significance test for differences between ranked treatments in an analysis of variance. Virginia J. Sci., 2(9): 171-189.

FDA, 1996. Fish and Fisheries Products Hazards and Controls Guide: First Edition. Department of Health and Human Services, Public Health Service, Food and Drug Administration, Center of Food Safety and Applied Nutrition, Office of Seafood, USA.

Finney, D. J. 1971. Statistical Method in Biological Assay, (2nd edn). Charles Griffin and Co. London, $668 \mathrm{p}$.

Jilani, G. and Saxena, R. C. 1990. Repellent and feeding deterrent effects of turmeric oil, sweetflag oil, neem oil, and a neem based insecticide against lesser grain borer (Coleoptera: Bostrychidae). J. Econ. Entom., 83: 629-634.

Khan, Y. S. A., Zabber, S. M. A. and Saifullah, A. S. M. 2002. Use of insecticides in dried fish and its effects on human body. Committee for Social and Environmental Development-COSED, $24 \mathrm{pp}$.

McDonald, L. L., Guy, R. H. and Speirs, R. D. 1970. Preliminary evaluation of new candidate materials as toxicant, repellent and attractant against stored product insects. Marketing Res. Report No. 882. Agric., Res. Serv. 5. Dept. Agric., Washington DC, 8 p.

Neuschler, H. 1998. Fish drying with the solar tunnel dryer type Hohenheim under Bangladesh conditions. Final Research Report. Institute of Agriculture Engineering in the Tropics and Sub-tropics, Hohenheim University, Stuttgart, Germany.

Nowsad, A. K. M. A. 2005. Low-cost Fish Processing in Coastal Bangladesh BGD/97/017, Field Dec: 5/2005. FAO. 88 pp.

Scngypt, C. E. and Ray, D. L. 1987, Derivations of piperic acid and their toxicity towards houseflies. Contribuce Boyce, Thompson Inst. 16: 433-442.

Sundaram, K. M. S. 1996. Azadirachtin biopesticide Bangladesh review of studies conducted on its analytical chemistry, environmental behavior and biological effects. J. Environ. Sci. and Health B., 31: 913-948.

Talukder, F. A. and Howse, P. F. 1993. Deterrents and insecticidal effect of extracts of pithraj, Aphanamixis polystachya (Meliaceae) Against Tribolium castaneum in storage. J. Pest. Manag., 40(1): 94-97.

Talukder, F. A. and Howse, P. F. 1994. Laboratory evaluation of toxic and repellent properties of pithraj, Aphanamixis polystachya Wall. Against Sitophilus oryzae L. Int. J. Pest. Manag., 40(1): 94-97. 